\title{
Does organizational culture support matter in elucidating the relationship between training ante- cedents and training effectiveness in Bahrain?
}

\author{
Ehsan Saeed Idrees Yaqoot ${ }^{\mathrm{a}}$, Wan Shakizah Wan Mohd Noor ${ }^{\mathrm{b}}$ and Mohd Faizal Mohd Isa ${ }^{\mathrm{b}}$
}

${ }^{a}$ Community Service \& Continuing Education Center, University of Bahrain, Bahrain

${ }^{b}$ School of Business Management, College of Business, Universiti Utara Malaysia, Malaysia

CH RON I C L E

Article history:

Received: January 28, 2020

Received in revised format:

January 302020

Accepted: February 29, 2020

Available online:

March 2, 2020

Keywords:

Social support

Training factors

Training effectiveness

Trainer

\section{A B S T R A C T}

\begin{abstract}
This paper intends to inspect the potential organizational culture moderating influence on the relation between trainer and social support and training effectiveness. The research model was established based on the theory of social cognitive (SCT), which involves training and organizational antecedents. We distributed 382 questionnaires, the returned questionnaires were only 155, and only 128 ones were valid. The hypotheses were assessed by SPSS version 23.0. The study examines training effectiveness and its determining factors. The results disclose that trainer, social support and organizational culture were associated with the nature of positive and significant type with training effectiveness. The findings represent that organizational culture had a partial significant and positive moderating effect on training effectiveness. This paper proposes to identify training effectiveness and its determining factors in the Bahraini public sector generally and local employees specifically. This is because there are limited similar studies in the perspective of Bahrain; therefore, the existing study presents abstract and practical implications for additional consideration for practitioners and administrators.
\end{abstract}

\section{Introduction}

Training fills gaps in the knowledge of the existing workforce by providing them with new skills and qualifications. Training is the major factor that maintains the required continuous knowledge improvement. Training is a shared operation between many parties. For example, a trainer is a qualified person and an expert in his field. Trainers should be fully aware of their major and can answer almost any question about it. According to Koskela and Palukka (2011), it is a two-directional interaction between the trainee and the trainer to equip the trainee with additional professional skills and capabilities. Skills and capabilities are considered to be of two types; gaining knowledge by studying and gaining knowledge by participation where the trainer can be the other party who is sharing his information. This implies the connection between cognitive apprentice relationships (Ligorio, 2010). The function of training effectiveness has turned to be extensively essential in the organization since training professionals have become strategic partners due to their ability in transferring and enhancing the capabilities and skills of the employees (Vazifeh et al., 2014). It is deemed as an element of the key strategy to build and approach a competitive sustainable benefit in a business environment (Descu, 2012). As such, training is growing to be more common although the subject is progressive in the academic arena. Training effectiveness is a very wide research area that can be researched from various angles (Al-Bahussin \& Elgaraihy, 2013). Effective training connects properly all the parties involved in the business those are organizations, employees, and customers by the practice of transferring knowledge gained by the employee from training in the work environment; therefore, it serves the organization's competitiveness ability including 
public sector organizations (Chen, Yang, \& Chen, 2010). Training effectiveness is a comparatively critical subject that public sector organizations are struggling to accomplish (Ali, 2010). Training effectiveness in any sector such as the public sector organizations can be defined as the process of improving and updating trainee's knowledge related to issues concerning public sector organizations, using the collaborative influence of training antecedents for improving the capabilities and skills among public sector workers (Driouchi, 2014). Effective training enables public sector workers, together with their organizations, to gain additional new knowledge as well as develop existing skills, expertise, and knowledge in the organizations in order to attain outstanding performance in their services (Ford, 2014). Therefore, it is significant for Human Resources (HR) professionals especially in the public sector to perform effective training toward advance employees' capacities. Researches confirmed that effective training forms a crucial instrument to expand organizational performance in any working environment type like the traditional public sector one (Olds, 2013).

Management in the public sector organizations in Bahrain is usually complaining about the availability of suitable and effective training programs to their employees especially in cases where performance and productivity are low and when their employees cannot possess the skills and knowledge, which cause customers dissatisfaction and duties fulfillment. Otherwise, their dissatisfaction is reflected to their loyalty, commitment and job satisfaction due to missing the capability to handle their duties (Almakhadmah, 2012). This indicates that effective training plays an essential function in the effectiveness of organizations in the public sector in Bahrain. It helps employees on the subject of better communication, integrate and perform their duties effectively (Ganesh \& Indradevi, 2015). Furthermore, the Bahraini public sector has been performing awfully, mainly because of training effectiveness and employees' performance-related problems. The problem of inadequate functioning in the public sector has been a subject of important discussions (Mboera et al., 2007). Regardless of the massive appointment in training public sector professional and substructure improvement, related costly disbursement, existing and available training organizations are facing difficulties in accomplishing the services quality level required from the public sector. The Bahraini public sectors did not achieve the desired performance from training institutions (Ngowi, 2009). Earlier studies about this subject have described that the sector's managements' capabilities to promote enlightenment of enhancing skills, proficiency, favorable needed job practices, and inspiration among employees are totally inconvenient so as to conquer the efficiency confronts of the different Bahraini public organizations (Norbert \& Lwoga, 2013).

The sector is in high need for many more studies, in addition to the very few available concerning ones to be enriched by more literature reviews and will focus mainly on the factors in direct relation with the training effectiveness and the worthwhile significance of the evaluation process. For that reason, this study meant to fill the identified gap by researching the moderating influence of organizational culture respecting the trainer and social support relation and training effectiveness. The current study contributes to the prevalent knowledge framework by presenting theoretical support to the view of trainer and social support by widening extenuating training effectiveness viewpoint. By incorporating organizational culture in the form of a moderator between the relations combining trainer, social support and training effectiveness, the current study helps in determining the factors that are anticipated to be moderated on training effectiveness. In the next section, it considers investigating the concerned literature, in addition, the hypotheses development and study's framework. After that comes the methodology, followed by results, and then comes the discussion, the methodology, results, discussion, implications, limitations, and suggestions for future research come after.

\section{Literature Review}

Training effectiveness is a major player component in any training implementation. It facilitates the utilization together with the creation of new knowledge (Hsu-Hsin Chiang, Tzu-Shian Han, 2011). Effective training facilitates the member of an organization to obtain knowledge and skills more conveniently and quickly; it aids the organization's members to create and utilize the existing knowledge and skills through the practice of enhancing them through training, which leads to improving their performance and knowledge utilization. Training effectiveness facilitates organizational invention, gaining competitive advantage, as well as improving both organizational and individual capabilities (Baskaran, 2018). Training effectiveness generally occurs by an interchange and incorporates knowledge's elements (Nahapiet \& Ghoshal, 1998). Higher standards and productivity varies with the training elements quality (Raza et al., 2014). Organizations need to encourage intelligence and knowledge improvement to help the formation of great advancement of performance. The expertise utilized in the work field is considered as the basic origin of challenging advantage, and the most significant organizational resource. Knowledge obtained resides in mind. It is digested by individuals and can be used to do things in a better way and method (Chan Kim, W., \& Mauborgne, 1998).

\subsection{Training Effectiveness}

School post-training in Bahrain is until now unknown and insubstantial in the awareness that it lucks proofs of its importance recorded in comparison to other gulf citizen countries (GCC). Other GCC countries periodically and frequently recheck their training-related programs and human resource rendering outputs corresponded with the actual needs of human resources and country (Karoly, n.d.). Labor Market Regulatory Authority (LMRA) presented that a big portion of the preference and highlevel responsibilities and high salary appointments are assigned to non-local human resources. Furthermore, every five Bahrainis employment in this sector receiving a salary that is more than BD 1500 , faced by the employment of one expatriate classified in the equivalent salary scale. This offers a shortage that necessities expatriates who are benefit is not limited to the highest salary range but also an unusual and up normal proportion matched to the Bahraini's salary. The show how important 
is training. It is significantly linked to the difficulties faced no matter what type of organization i.e. the unavailability in the human resources' expertise and inadequacy in the educational system available (Al-Mahdi, 2014). The appraisal of performance was unclear for much of time from point of view of the management, implementation, and design. The cause of that was because of employing inappropriate operational approaches (Davis, 2012). Training functions to deal with the difficulties and to advance outcomes. It promotes the individual and the organization. Furthermore, extra researches and studies should be performed related to this subject to set up a foundation for further care and attention to the significance of effective training. A grown necessity for highly qualified employees is connected with a grown complication in the work fields. Training is also named continuing education. Government agencies employ training for the upgrading of their employees' performance. Effective training offers organizations with lots of advantages unlimited to finding solutions for existing and future crises that the organization may encounter. Furthermore, It helps with adjustment with current's turbulent settings (Bimpitsos \& Petridou, 2012). Understanding the continuing education effectiveness is necessary because of its importance and the change it can create. It is not just imperative in the delivery of urban services to the society, but it is also needed as a stimulant in economic enhancement and the nation's well-being. Effectiveness stands for the attainment of the planned goal. It additionally stands for the probability of affording a proper active setting to achieve the purpose that was set. Training anticipation does not mean simply joining or passing by a training program. It is supposed to locate the participant in an altered knowledge stage. Baraki \& Kemenade (2013) mentioned that training advances the nations by heightening the empowerment, harmony, learning, knowledge, and participants' caution. The objective of the training assessments is the definition of its worth and its utility or advancements moreover its effectiveness (Kirkpatrick, 1970). This is worthy of attention to compare the real cost of program to the interacted potential benefits. Thus, it confirms whether the program could deliver the intended advantages (AlYahya \& Norsiah, 2013). Training is similar to everything. It needs logical structured systematic approaches and processes to achieve its main intent to aid in advancing the human resources' skills in the job field (Khalid, 2012). It is also meant to supports the organization's intentions in enhancing the employees' capacity by a series of activities conducted to attain that. The process of training involves activities that connect the learner with other people, devices, materials, tools, etc. (Kock $\&$ Ellström, 2011). The public sector conducts training to inspire the employees to gain a state-of-the-art and an up to date abilities to perform something in a better way. Training sessions that were prearranged to be effective will serve the organization in reaching the organization's main goal and its employees' intention (Karim et al., 2012). Effectiveness verifies the training's status if it is either advantageous or if it did not produce the wanted advantages (Saghafian, 2011). The training's transfer advantage is in fact limited to 10-15 percent only. The complete training's potency under no condition is fully achievable. Full training's potency utilization in the workplace is the desire for any training's program. This is one of the central considerable factors behind the training's objective to enhance both parties' performance (Griffin, 2011).

The vocational and developmental training programs had been favored mainly for the present study. These training programs are strongly demanded skills improvement intended to develop staff's capabilities in the public sector. This kind of training program is designed typically to suit the different employee's levels in the organizations including supervisors and clerks and is classified as an essential program. These employees' groups are expected to participate in these training programs on every occasion specifically in the course of their preparation period because those programs prepare them with the required employment skills. Falling to do so restrains their performing with their restricted prior knowledge. The purpose behind these vocational training programs is to provide employees with the essentials to reinforce their career productivity. These programs concentrate mainly on the job demanded knowledge and neglect other unnecessary subjects that are in an indirect relationship to the employee's nature of work. The training program consists usually of a workshop that incorporates both classroom discussions and practices. During the training course, the participants will also learn additional knowledge as a cause of sharing other instructors and participants' experiences. Trainee's performance is also complemented with additional indirect skills that will also influence their performance in general. Therefore, their desire to apply new knowledge in their work is important. These courses' period is not fixed. It is dependent on the requirement and the plan. It can also be based on participants' number and according to their existing capability level.

\subsection{The Theory of Social Cognitive}

The Theory of Social Cognitive (SCT) alludes to a psychological model of behavior that protrudes essentially from the work of Bandura (1986). In the beginning, it is developed with an affirmation on the subject of social behavior, SCT continues to confirm the occurrence of leaning in a social context and a big portion of what is learned is obtained by observation. SCT has been widely utilized in human functioning areas such as organizational behavior, and career choice. It has also been utilized broadly by practitioners concerned about studying class learning, trainee motivation, and training achievement (Pajares, 1996). According to Jdaitawi (2012), SCT relies on various principal assumptions about behavior and learning. One of the assumptions is related to triadic reciprocity, or the relationship between behavioral, personal, and environmental factors and the way they influence each other in a reciprocal, bidirectional manner. That is, a person's performance is a result of a continuous interaction between contextual, behavioral and cognitive factors. For example, training is shaped by factors exists inside the training environment, especially the enforcement experienced by others' support like trainer's and other trainee's support. At the same time, training effectiveness is affected by trainees' self-beliefs, own thoughts, and trainee's motivation (Massenberg et al., 2015). A closer look within SCT related assumption indicates that trainees can influence the environment and their behavior in a motivated, goal-directed manner, and better-tuned training antecedents (Bandura, 2001). This assumption disagrees with other behaviorism forms that confirmed a primmer form of environmental specifically determinism. SCT is not 
against the significance of the training environment in determining behavior, however, it argues that trainee can also, through early planning, self-regulatory processes, self-reflection, increases training effectiveness through outcomes enhancement of training antecedents including training environment and trainee's outcomes (Ford, 2014). The third SCT related assumption stating that training effectiveness does not require an immediate change in behavior or more broadly, that training effectiveness and training transfer are distinct processes. One reason for this detachment is that SCT also presumes that training effectiveness involves not just gaining of new or change in behaviors, but also of abstract rules, cognitive skills, knowledge, values, and other cognitive constructs (Chiaburu et al., 2010).

\subsection{Trainer}

The trainer's principal job is to transfer the information presented in the training material to clear knowledge to benefit the trained trainee in conduct that permits the attainment of the wanted outcomes. In addition to smooth the training implementation requirements, like using the suitable presentation skills, a well-prepared environment, using the suitable training material, the trainer should be suitably planned for the course (Lin, 2012). The trainer is a necessary variable in any training program type. The trainer's principally wanted characteristic is the knowledge in a specific subject related directly to the training program. However, specialty in a particular subject is not enough and must be complemented by the capacity to transfer it articulately and clearly to the trainees (Ghosh et al., 2012). Iqbal et al. (2011) abbreviated the most crucial responsibility played by the trainer in the trainees' learning and reaction. The participants' motivation to learn, eliminating their uncertainty, treating any undesirable previous experiences or observations related to the training course are also the trainer's role. Also, the completion of antecedent training programs was normally due to the trainer's personality (Ghosh et al., 2012). The shortage of demonstration discourages the knowledge transferability to the trainees. The appropriate trainer is the one who can clarify the new information and ideas easily while complementing them with real useful related examples (Griffin, 2014).

\subsection{Social Support}

Training effectiveness is in direct link with the training transmission. Social support calls for further research because of its limited and inappropriate investigation. Additional research is demanded because generally the scholars in the training relocation their study's focus into their limited vision of just either the supervisor's or the organization's support. Training accomplishment does not occur without the surrounding people's social support encouragement that might be also from either the organization or the supervisor; it demands other people like the other training participants, or a member of the family by promoting the suitable atmosphere that motivates the trainee to learn. Social support motivates the person to learn and increase their knowledge, it additionally has an affirmative impact on a person's self-efficacy (Chiaburu et al., 2010). Employee's productivity and performance are increased straightforwardly by the culture of the organization and the support provided by the colleagues and organization, specifically the people in direct contact and relationship with the trainee. An environment that is of beneficial conduct and encourages employee's creativity will increase the chances that help functionality and yield beyond what the organization wanted. The reason behind this related to the positive motivation's influence on the trainees resulting from the supportive environment that motivates their productivity, behavior, and favorable presentation of their organization (Raza et al., 2014). To maximize training investment benefits in the public sector, an encouraging organization setting is strongly needed to broaden the encouragement of joining and utilizing the obtained skill and knowledge for the work field advantages (McCracken et al., 2012). Because of the multiple difficulties the training professionals and managers encounter currently such as the increased fast demand for new sorts of skills, limited available training budget, and universal complication, organizations started to search and focus on any support they can get. With their affirmation in the possibility of treating almost all the performance-related problems using training, management is needed to give the training subject the desirable attention. For example, they should arrange for the required by the organization training courses, facilitate employees' training and participation, and solve any issue that may exist in the training process. Management is also needed to understand that the improved skills and knowledge the employee get, the improved productivity and quality refunded back to the organization. Management authorization and selection for the training courses to furtherance and improve them is truly esteemed, or otherwise the employee's gaining will not be approachable (Punia \& Saharan, 2012).

\subsection{Organizational Culture}

They describe organizational culture as an attitudes' mixture of both the employees and the administration, sort of control applied in the organization, roles, and policies of conduct. It determines the general methodology to look after all the subjects related to the process of the activities to run the organization. It also takes the required procedures to fine-tune them based on requirements. Its main concern is to supervise the behavior of the employees (Raza et al., 2014). While training is a performance enhancement strategy to optimize the productivity by the enhancement of the trainee's skills and capabilities, effective training helps the organization to implement its objectives, and assists putting in applications the type of culture it wants to implement (Karim et al., 2012). Hartog and Verburg (2004) described it as a set of assumptions, acceptable practices, and values in addition to policies shared between parties in an organization and explained to employees as appropriate.

\subsection{The Roles of the Moderator}

According to the literature, organizational culture represents a considerable role in moderation. George and Jayan (2013) discovered that it moderates the relation between job attitude and personal effectiveness in the job field such as training 
effectiveness relationships. Furthermore, it has been shown that social support construct is related to it (Aksoy et al., 2014). Nevertheless, they did not additionally consider the organizational culture moderating influence on the relation between trainer together with the social support into the training effectiveness. To clarify the possible organizational culture role as a moderator, George and Jayan (2013) are invoked. They proposed that organizational culture would produce a crucial social force that moderates the organizational atmosphere effect on the employees' desire to implement the information gained in the training. The governmental atmosphere is principally intended for attaining correspondingly organizational together with individual objectives (Raza et al., 2014). Because trainer and social support are responsible for an individual's and of individual's organization's successful result (Brown, 2010), it is right to indicate that they will be evoked as an organizational culture that can be used as a moderating variable between trainer, social support and training effectiveness. Based on the prior study conducted by Chiaburu et al. (2010), stating that assorted factors' influence into training effectiveness such as trainer and social support are moderated by organizational culture. On the other hand, Sukserm and Takahashi (2012) determined that organizational culture can form a strategic development useful tool to motivate the human resources to enhance the existing skills, acquaintance, their attitude change, especially in terms of developing a more conducive mindset like training. Bearing in mind the theory of social cognitive, an individual who has affirmative experience regarding the organization gains from, as well from that positive atmosphere, and is likely to performance's enhancer behavior. Therefore, the relation between training effectiveness, social support, and trainer may be moderated by organizational culture. Thus, hypotheses 4 and 5 are proposed accordingly.

\section{Conceptual Framework}

Fig. 1 represents the research framework. It shows the theoretical relation through the established framework contents, the dependent variables, and the independent variable. The effectiveness of training represents the dependent variable herewith. Trainer and social support in the other hand consisting the antecedents that affect the training effectiveness forming the independent variables. The collected quantitative data forms the analysis method foundation for the current study. The analysis of the training effectiveness level of concern is established on the trainees' gathered data.

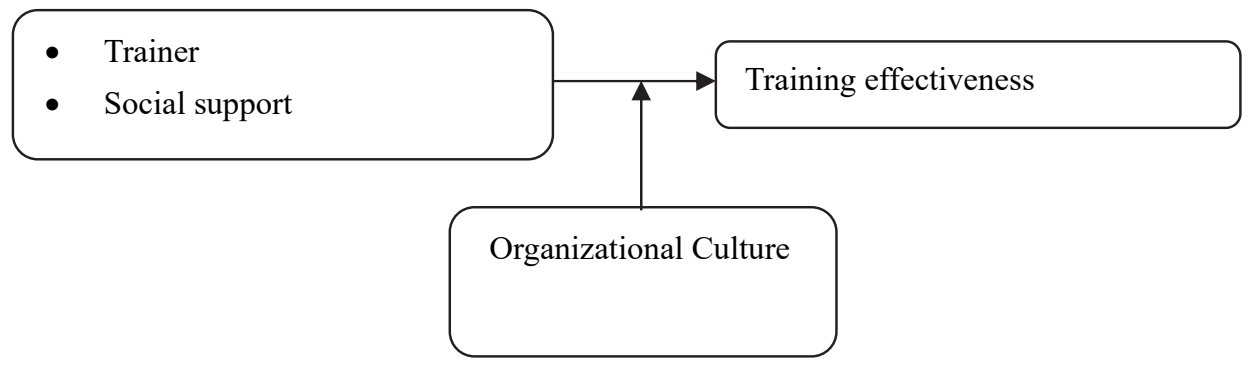

Fig. 1. Research Framework of the Study

\subsection{Hypotheses}

A positive and significant relationship has been determined in previous studies between training effectiveness, organizational culture, trainer, and social support. Although a number of those studies presented inconsistent results that call for more research about this subject. Thus, the proposed hypotheses were suggested to clear further the argument regarding the factors affecting training effectiveness.

$\mathrm{H}_{1}$. There is a significant relationship between trainer and training effectiveness.

$\mathrm{H}_{2}$. There is a significant relationship between social support and training effectiveness.

$\mathrm{H}_{3}$. There is a significant relationship between organizational culture and training effectiveness.

$\mathrm{H}_{4}$. The organizational culture moderates the relationship between the trainer and the training effectiveness.

$\mathrm{H}_{5}$. The organizational culture moderates the relationship between social support and training effectiveness.

\section{Method}

Differentiating the suitability between the approaches for measuring accompanied by rationalization, a quantitative questionnaire instrument with Likert five points was determined to be the suitable rating scale. A pilot test is performed at first for checking the reliability of the instrument. Thirty approachable public sector employees who participated previously in the training program were requested to complete the questionnaire. The obtained Cronbach's Alpha values presented 0.939 related to the trainer, 0.839 related to the training environment, and 0.939 related to the training effectiveness. Referring to Mayr et al. (2007), 89 employees is the appropriate sample choice for public sector employees' population equivalent number of 39,286 . Three months at least should be completed after attending a training program is preserved as a principle (Kirkpatrick, 1970). Supervisors and clerks were the only intended respondents. Even with the repeated efforts made for questionnaires returning, 
only 155 were returned. 27 questionnaires were excluded because of their incomplete filling. 128 samples are analyzed as it is above the minimum sample size needed. The shortage in the obligation rate is related to the research disappointed culture Arabian public is familiar with (Gelaidan, 2012). Hence, to raise the probability of obtaining a healthier and precise response from a questionnaire conducted in an Arabic nation, it was additionally converted to the native language, which is Arabic with assistance from bilingual specialists working in the English Language Center at the University of Bahrain.

\subsection{Measurement of Items Virtuous}

The questions of the questionnaires applied are obtained from other related studies conducted in the same field. Items were adopted and examined to meet the aim of this study. The questions for independent factors and the dependent factor were assessed to examine the respondents' answer with the use of five-point Likert scale. The five-point Likert scale varies from strongly agree (5) to strongly disagree (1). The questionnaire comprised four sections including respondent demographic. Six (6) items measured training effectiveness (result) adopted from previously conducted studies. Five items of them were taken from Barker (1997). One more item was from Tai (2006). Fifteen (15) items measured the trainer adopted from Leach (1996). Sixteen (16) items measured the social support obtained from Burke \& Baldwin (1999). Thirty-one (31) items measured the organizational culture obtained from Glaser, Zamanou, \& Hacker (1987). Items validity examined for all the items attained acceptable validity requirements, SPSS version 23 for data analyses was the Statistical Package.

\section{Results}

Cronbach's alpha calculation indicates the respondents' agreement level for every factor. Higher reliability means a higher value. The extent ranges between 0 and 1 . The larger dimensions part scored high-level reliability. Particularly, values were above the designated limit amount of 0.70 referring to Pallant (2002). The smallest figure obtained from trainer 0.870 (higher than 0.7 and acceptable), social support presented the maximum figure of 0.910 . The obtained figure for the dependent variable training effectiveness was an acceptable figure of 0.960. Instant Statistics illustrates the evaluation applied to determine the relation among the dependent variable (training effectiveness) and independent variables (trainer, social support) in this section. In the beginning, the descriptive statistics outcomes together with the analysis for relationship for both the dependent and independent factors are displayed. Followed by the multiple regression sort of testing to demonstrate in a statistically form the training antecedents contribution level in the training effectiveness. The reliability of the questionnaire's items is statistically checked by theoretic appraisal.

\subsection{Descriptive Results}

Based on the data obtained from the descriptive statistics, the larger participant's part is referring to male (58.6\%) confronted with $41.4 \%$ for females. This is in opposition to the ideas stating that female is usually the higher employees' percentage in the public sector. Moreover, based on the participants' age which differ between 20-29 (14.8\%), 30-39 (54.7\%), 40-49 (19.5), $(10.9 \%)$ for 50 and above. It presents that the participants' larger part is in the midpoint age This age means productivity for long period serving the organization, and not reaching retirement very soon. The approached outcomes reinforce the demand to target this classification's performance taking into account they present the ideal human resources for this sector. With reference to the experience of participants, the results show that (12.5\%) is the less than 5 years ratio, $(30.5 \%) 6-10,(26.6 \%)$ $11-15,(8.6 \%) 16-20,(21.9 \%)$ for 21 and above. More than half is classified at the establishment of the businesslike life where they are new, require the fundamental experience, and formulate a suitable group for training for reaching their top production for years to come.

\subsection{Correlation}

Referring to the delivered variables 'analysis results, which identified the high-value inter-item relationship appears between them all. Table 1 represents the correlation' results between training effectiveness, training environment, and trainer. The trainer and social support are correlated significantly with training effectiveness. This confirms that hypotheses from H1, to $\mathrm{H} 3$ including $\mathrm{H} 2$ are valid and represent a relationship of positive nature between training effectiveness, training environment, and trainer.

Table 1

Correlation results

\begin{tabular}{lccc} 
& Trainer & Social Support & Organizational Culture \\
\hline Trainer & 1 & & Training Effectiveness \\
Social Support & $.400^{* *}$ & 1 & $.647^{* *}$ \\
Organizational Culture & $.383^{* *}$ & $.619^{* *}$ & 1 \\
Training Effectiveness & $.275^{* *}$ & $.526^{* *}$ & 1 \\
\hline
\end{tabular}

** Correlation is significant at the 0.01 level (2tailed).

\subsection{Regression Analysis}

Table 2 represents multiple regression analysis outcomes. It shows the trainer and the social support variables' influence contribution to training effectiveness. The recorded results represent that $0.384(38.4 \%)$ is the contribution extent of social 
support and trainer together to training effectiveness. It indicated that $38.4 \%$ of the variance in training effectiveness could be related to these particular individual variables dimensions. The social support represents a higher training effectiveness impact represented numerically by .606 as a beta value compared with the trainer's influence that generated a beta value of .033 .

Table 2

Regression results dependent variable: Result (Training effectiveness)

\begin{tabular}{lccc}
\hline Variables & Beta & T-ratio & Sig. t \\
\hline Trainer & .033 & .425 & .672 \\
Social Support & .606 & 7.781 & .000 \\
\hline
\end{tabular}

R Square $=0.384$ F-value $=37.722(0.000)$ Durbin-Watson $=1.852$

\subsection{Hierarchical Regression Analysis}

The significant incremental $\mathrm{R}$ square reported in Table 3 revealed that the influence of social support was moderated by organizational culture. The sign of the interaction terms was statistically significant in the predicted direction. Thus, an inspection of individual interaction terms between social support *organizational culture - $>$ training effectiveness $(\mathrm{p}<0.000 * *)$, (H5) confirms the moderating influence of organizational culture in the relationship between training effectiveness and social support at $\mathrm{P}<0.05$ level of significance. Thus, H5 was supported. According to Sharma et al. (1981), it is concluded that organizational culture appeared to be an effective moderator variable in the relation combining social support and training effectiveness. However, the results also showed that the interaction between trainer * organizational culture $\rightarrow$ training effectiveness $(p<.529 \mathrm{NS})$, were not significant. This denies the possible moderating influence from the organizational culture in the relationship between trainer, and training effectiveness at $\mathrm{P}<0.05$ level of significance. Hence, the H4 is rejected. The outcomes of the hierarchical multiple regression examination of the moderating impact are presented in Table 3. For H5, the organizational culture moderating effects on the relation between training effectiveness and social support is supported. This implies that social support is altered through the organizational culture, which consecutively, influences the training effectiveness.

Table 3

Hierarchical regression result for the organizational culture moderating effect on the trainer, and social support and Training Effectiveness.

\begin{tabular}{|c|c|c|c|}
\hline Variables in the Model & $\begin{array}{c}\text { Model } 1 \\
\text { Independent variable }\end{array}$ & $\begin{array}{c}\text { Model } 2 \\
\text { Moderating variable }\end{array}$ & $\begin{array}{c}\text { Model } 3 \\
\text { Interaction variable }\end{array}$ \\
\hline Trainer & $0.672^{\mathrm{NS}}$ & 0.988 & $0.529^{\mathrm{NS}}$ \\
\hline Social Support & $0.000 * * *$ & 0.000 & $0.000 * * *$ \\
\hline F change & 37.722 & 5.353 & 4.271 \\
\hline Sig. F change & .000 & .022 & .016 \\
\hline $\mathrm{R}^{2}$ & .384 & .410 & .450 \\
\hline Adjusted $\mathrm{R}^{2}$ & .374 & .396 & .427 \\
\hline $\mathrm{R}^{2}$ change & .384 & .026 & .040 \\
\hline
\end{tabular}

$* \mathrm{P}<0.10, * *<0.05, * * * \mathrm{p}<0.001$, Sig $=$ Significant, $\mathrm{NS}=$ Not Significant

\section{Discussion}

According to the theory of social cognitive, the present study proposes to test the organizational culture moderating effects on the relation combining trainer, social support and training effectiveness. To display the potential influence on training effectiveness, the study's context is underpinned by the theory of social cognitive. The data analysis indicated results show that the conclusions are unvarying with literature and theory. The concluded outcomes in this study show the positive significant relationship connecting together the training effectiveness and the trainer. These outcomes are parallel with past studies similar to the one conducted by Griffin (2014), declaring the significant relationship among the trainer and the training effectiveness. This supports hypotheses H1. It thus means that in the real world the trainer can produce an effective influence to a great degree, and control the trainees' response in the public sector in Bahrain to the training programme. Conversely, the study's outcomes also indicated that social support was not significant in predicting training effectiveness as such hypotheses H2 was not supported in its second portion.

\section{Research Limitations and Guidance for Future Research}

The present study suffers from various limits. For instance, it does not touch comprehensively other factors that might influence training effectiveness. Examples of these factors can be gender, age, and tenure can take the form of demographic forming demographic factors (Bock et al., 2005). The possible impact of these influential variables on training effectiveness is not inspected in the current study. Accordingly, further studies could cover these variables to identify their probable influence. In addition, it is not possible to generalize the outcomes obtained from this study, because it was implemented in Bahraini public sector organization, focusing only on governmental sector employees, who are categorized by their collective culture. Thus, additional studies are required in different geographical settings, cultures, and contexts to popularize the outcomes. 


\section{Conclusion}

The current study suggests a model for the moderating effects of organizational culture on the relationship between trainer, social support and training effectiveness in the public sector context. The findings indicate that trainer, social support and organizational culture have a positive and significant effect on training effectiveness. However, organizational culture portrays a partial positive and significant moderating effect on the relationship between trainer, social support and training effectiveness. All the exogenous factors were determined as the most effective predictors of training effectiveness amount the public sector professionals. Thus, the management of public sector organizations must pay attention to designing activities, programmes, and preparing encouraging organizational cultures to promote positive job characteristics, career advancement, and affirmative social support to propagate training effectiveness.

\section{References}

Aksoy, M., Apak, S., Eren, E., \& Korkmaz, M. (2014). Analysis of the effect of organizational learning-based organizational culture on performance, job satisfaction and efficiency: A field study in banking sector. International Journal of Academic Research, 6(1), 301-313.

Al-Bahussin, S. A., \& Elgaraihy, W. H. (2013). The impact of human resource management practices, organisational culture, organisational innovation and knowledge management on organisational performance in large Saudi organisations: structural equation modeling with conceptual framework. International Journal of Business and Management, 8(22), 120.

Al-mahdi, O. (2014). Towards improving the quality of technical and vocational education and training in Bahrain. International Journal of Pedagogical Innovations, 2(2), 73-82.

Ali, F. M. (2010). New public management and administrative reforms in the kingdom of Bahrain: implementing performance and programme-based budgeting (Issue September). (Doctoral dissertation, University of Hull, 2010).

Almakhadmah, I. (2012). Factors influencing the effectiveness of human resource training programmes in hotel sector [(Doctoral dissertation, Universiti Utara Malaysia, 2012)]. http://etd.uum.edu.my/3437/

AlYahya, M. S., \& Norsiah, B. M. (2013). Evaluation of effectiveness of training and development: the Kirkpatrick model. Asian Journal of Business and Management Sciences, 2(11), 14-24.

Bandura, A. (1986). The explanatory and predictive scope of Self-Efficacy theory. Journal of Social and Clinical Psychology, 4(3), 359-373.

Bandura, A. (2001). Social cognitive theory: An Agentic Perspective. Annual Review of Psychology, 52(1), 1-26.

Baraki, A. H., \& Kemenade, E. Van. (2013). Effectiveness of technical and vocational education and training (TVET): insights from Ethiopia's reform. The TQM Journal, 25(5), 492-506. https://doi.org/10.1108/TQM-11-2012-0099

Baskaran, S. (2018). Mediation effect of knowledge management enablers on the relationship between organizational characteristics and entrepreneurial orientation. Gadjah Mada International Journal of Business, 20(1), 1-32.

Bimpitsos, C., \& Petridou, E. (2012). A transdisciplinary approach to training: preliminary research findings based on a case analysis. European Journal of Training and Development, 36(9), 911-929. https://doi.org/10.1108/03090591211280964

Bock, G., Zmud, R. W., Kim, Y., \& Lee, J. (2005). Behavioral intention formation in knowledge sharing: Examining the roles of extrinsic motivators, social-psychological forces, and organizational climate. MIS Quarterly, 29(1), 87-111.

Brown, T. (2010). Making Training Strategic. Public Manager, 39(2), 38-43.

Burke, L. A., \& Baldwin, T. T. (1999). Workforce training transfer: a study of the effect of relapse prevention training and transfer climate. Human Resource Management, 38(3), 227-241.

Chan Kim, W., \& Mauborgne, R. (1998). Procedural Justice, Strategic Decision Making, and the Knowledge Economy. Strategic Management Journal, 19(4), 323-338.

Chen, K., Yang, S., \& Chen, M. (2010). Increasing national competitiveness in terms of the human resource commercialization as well as delegation and empowerment of public sector. Journal of Global Business Management, 6(1), 9-1.

Chiaburu, D. S., Dam, K. Van, \& Hutchins, H. M. (2010). Social support in the workplace and training effectiveness: A longitudinal analysis. International Journal of Selection and Assessment, 18(2), 187-200.

Davis, P. J. (2012). Seven biggest problems with performance appraisals: and seven development approaches to rectify them. Development and Learning in Organizations, 26(1), 11-14. https://doi.org/10.1108/14777281211189119

Descu, A. V. L. Ă. (2012). The possibility of implementing talent management in the public. Management \& Marketing Challenges for the Knowledge Society, 7(2), 351-362.

Driouchi, A. (2014). Unemployment persistence \& risks of skill obsolescence in Arab countries. 53793. http://mpra.ub.unimuenchen.de/53793/

Ford, J. K. (2014). Improving training effectiveness in work organizations. Psychology Press.

Ganesh, M., \& Indradevi, R. (2015). Importance and Effectiveness of Training and Development. Mediterranean Journal of Social Sciences, 6(1), 334-338.

Gelaidan, H. M. H. (2012). The moderating effects Of organisational culture on the relationship between leadership style and employee commitment to change of public sector in Yemen. (Doctoral dissertation, College of Business, Universiti Utara Malaysia, 2012).

George, R., \& Jayan, C. (2013). Moderating role of organizational culture on job attitude and personal effectiveness. Anvesha, 6(4), 18-22.

Ghosh, P., Satyawadi, R., Joshi, J. P., Ranjan, R., \& Singh, P. (2012). Towards more effective training programmes: a study 
of trainer attributes. Industrial and Commercial Training, 44(4), 194-202. https://doi.org/10.1108/00197851211231469

Glaser, S. R., Zamanou, N., \& Hacker, K. (1987). Measuring and interpreting organizational culture. Management Communication Quarterly, 1(2), 173-198. http://www.ncbi.nlm.nih.gov/pubmed/2189967

Griffin, R. (2011). Seeing the wood for the trees: workplace learning evaluation. Journal of European Industrial Training, 35(8), 841-850. https://doi.org/10.1108/03090591111168357

Griffin, R. (2014). Complete training evaluation: the comprehensive guide to measuring return on investment. (1st Editio). Kogan Page. https://books.google.com.bh/books?id=r_kOBAAAQBAJ\&printsec $=$ frontcover $\# \mathrm{v}=$ onepage \&q\&f=false

Hartog, D. N. Den, \& Verburg, R. M. (2004). High performance work systems, organizational culture and firm effectiveness. Human Resource Management Journal, 14(1), 55-78.

Hsu-Hsin Chiang, Tzu-Shian Han, J. C. (2011). The relationship between high-commitment HRM and knowledge-sharing behavior and its mediators. International Journal of Manpower.

Iqbal, M. Z., Maharvi, M. W., Malik, S. A., \& Khan, M. M. (2011). An empirical analysis of the relationship between characteristics and formative evaluation of training. International Business Research, 4(1), 273-286.

Jdaitawi, M. T. (2012), the Effect of Emotional Intelligence Training Program on Social and Academic Adjusment Among First Year Jordanian University Students. (Doctoral dissertation, College of Business, Universiti Utara Malaysia, 2012).

Karim, M. R., Huda, K. N., \& Khan, R. S. (2012). Significance of training and post training evaluation for employee effectiveness: an empirical study on Sainsbury's supermarket ltd, UK. International Journal of Business and Management, 7(18), 141-149.

Karoly, L. a. (n.d.). The role of education in preparing graduates for the labor market in the GCC countries. Working Paper Series WR- 742. https://doi.org/10.2139/ssrn.1554716

Khalid, M. M. (2012). Proposing a training evaluation strategy to ensure training transfer in public sector organizations in Pakistan: an exploratory account. 2(1), 111-121. https://doi.org/10.5296/ijhrs.v2i1.1195

Kirkpatrick, D. L. (1970). Evaluation of training. In Evaluation of short-term training in rehabilitation (p. 35). Rehabilitation Research and Training Center in Mental Retardation at the University of Oregon.

Kock, H., \& Ellström, P.-E. (2011). Formal and integrated strategies for competence development in SMEs. Journal of European Industrial Training, 35(1), 71-88. https://doi.org/10.1108/03090591111095745

Koskela, I., \& Palukka, H. (2011). Trainer interventions as instructional strategies in air traffic control training. Journal of Workplace Learning, 23(5), 293-314. https://doi.org/10.1108/13665621111141902

Leach, J. A. (1996). Distinguishing characteristics among exemplary trainers in business and industry. Journal of Vocational and Technical Education, 12(2).

Ligorio, M. B. (2010). Dialogical relationship between identity and learning. Culture and Psychology, 16(1), 93-107.

Lin, A. Bin. (2012). The Influence of Employee of Contextual Factors on Training Effectiveness of Technical Employees at Silterra Malaysia Sdn. Bhd [(Doctoral dissertation, School of Business, Universiti Utara Malaysia, 2012)]. http://etd.uum.edu.my/3426/

Massenberg, A. C., Spurk, D., \& Kauffeld, S. (2015). Social support at the workplace, motivation to transfer and training transfer: a multilevel indirect effects model. International Journal of Training and Development, 19(3), 161-178. https://doi.org/10.1111/ijtd.12054

Mayr, S., Buchner, A., Erdfelder, E., \& Faul, F. (2007). A short tutorial of GPower. Tutorials in Quantitative Methods for Psychology, 3(2), 51-59. https://doi.org/10.1037/0096-1523.32.4.932

Mboera, L. E. G., Rumisha, S. F., Senkoro, K. P., Mayala, B. K., Shayo, E. H., \& Kisinza, W. N. (2007). Knowledge and health information communication in Tanzania. East African Journal of Public Health, 4(1), 33-39.

McCracken, M., Brown, T. C., \& O'Kane, P. (2012). Swimming against the current: understanding how a positive organisational training climate can enhance training participation and transfer in the public sector. International Journal of Public Sector Management, 25(4), 301-316. https://doi.org/10.1108/09513551211244124

Nahapiet, J., \& Ghoshal, S. (1998). Social capital, intellectual capital and the organizational advantage. The Academy of Management Review, 23(2), 242-266.

Ngowi, H. P. (2009). Economic Development and Change in Tanzania since Independence: The Political Leadership Factor. African Journal of Political Science and International Relations, 3(4), 259-267.

Norbert, G. L., \& Lwoga, E. T. (2013). Information seeking behaviour of physicians in Tanzania. Information Development, 29(2), 172-182. https://doi.org/10.1177/0266666912450449

Olds, J. H. (2013). Refresher training: considerations in the public sector. Professional Safety, 58(2), 44-49.

Pajares, F. (1996). Pajares - Self-Efficacy Beliefs in Academic Settings.pdf. Review of Educational Research, 66(4), $543-578$.

Pallant, J. (2005). SPSS Survival Manual: A step by step guide to data analysis using SPSS for Windows (Version 12). In Allen \& Unwin (2nd edn.). Allen \& Unwin. https://doi.org/10.1046/j.1365-2648.2001.2027c.x

Punia, B. K., \& Saharan, T. (2012). Management approach and conditions of training: a relative study of service and manufacturing industries. Vision: The Journal of Business Perspective, 15(3), 239-250.

Raza, H., Anjum, M., \& Zia, S. M. (2014). The impacts of employee's job performance behavior and organizational culture on organizational productivity in pharmaceutical industries in Karachi. Interdisciplinary Journal of Contemporary Research In Business, 5(12), 385-400.

Saghafian, M. (2011). A critical review of research on technology-based training in business organizations. Research in Higher Education Journal, 10, 1.

Sharma, S., Durand, R. M., \& Gur-Arie, O. (1981). Identification and analysis of moderator variables. Journal of Marketing 
Research, 18(3), 291-300.

Sukserm, T., \& Takahashi, Y. (2012). Self-efficacy as a mediator of the relationships between learning and ethical behavior from human resource development in corporate social responsibility activity. Asia-Pacific Journal of Business Administration, 4(1), 8-22. https://doi.org/10.1108/17574321211207944

Tai, W. (2006). Effects of training framing, general self-efficacy and training motivation on trainees' training effectiveness. Personnel Review, 35(1), 51-65. https://doi.org/10.1108/00483480610636786

Tansu Barker, A. (1997). Determinants of salesforce effectiveness: perceptions of field managers versus senior sales executives. Marketing Intelligence \& Planning, 15(6), 258-264. https://doi.org/10.1108/02634509710184839

Vazifeh, Q., Damirchi, \& Kazemian, M. (2014). The Effect of Workers In-Service Training on their Self- Confidence at Health Organization of Mazandaran. International SAMANM Journal of Business and Social Sciences, 2(1), 1-13.

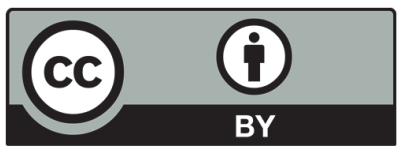

(C) 2020 by the authors; licensee Growing Science, Canada. This is an open access article distributed under the terms and conditions of the Creative Commons Attribution (CC-BY) license (http://creativecommons.org/licenses/by/4.0/). 